\title{
XXXVIII. Description of a new apparatus proposed for restoring the action of the lungs in cases of suspended respiration
}

\author{
John Moore Jun. Esq.
}

To cite this article: John Moore Jun. Esq. (1822) XXXVIII. Description of a new apparatus proposed for restoring the action of the lungs in cases of suspended respiration , Philosophical Magazine Series 1, 59:287, 169-171, DOI: 10.1080/14786442208652712

To link to this article: http://dx.doi.org/10.1080/14786442208652712

册 Published online: 29 Jul 2009.

Submit your article to this journal $₫$

Џ Article views: 2

Q View related articles $₫$ 
gases in tin plate vessels, and have invariably found that the vessels were torn open without the least danger to those present, as stated in my last communication.

In all the experiments above alluded to, I have used a mixture of nine parts by measure of hydrogen, and four parts of oxygen (prepared from hyper-oxymuriate of potash).

In justice to myself, and with reference to Mr. Murray's letter to you accompanying my paper, allow me to observe, that though Mr. Murray recommended the mercury in preference to oil or water, both the safety-cistern, and valve therein described were entirely my own invention ; and neither suggested by nor modified from any plan of that gentleman's.

$$
\text { I remain, sir, }
$$

Yours most obediently,

H. B. LEESON.

XXXVIII. Description of a new Apparatus proposed for restoring the Action of the Lungs in Cases of suspended Respiration. By J. Moore, Jun., Esq.

\section{To Dr. Tilloch.}

SIR, - $\mathrm{H}_{\text {AVING observed, in your Number for October last, a }}$ drawing and description of an apparatus by Mr. J. Murray, wherewith the action of the lungs might be restored, and having also a plan to effect the same desirable object, which 1 consider more complete that than gentleman's, as it does not require turning a cock to admit fresh air, but every time the pistons are raised and depressed not only gives a fresh supply to the lungs, but also withdraws the air which has been injected; I presume you will have the goodness to insert the following in your Magazine.

Let fig. 1 (PI. III.) represent a common air syringe with a solid piston, but thus differently formed, that at the bottom of the cylinder there are two tubes, as $A$ and $B$, either flexible or otherwise, each tube having a valve, that of $A$ having its valve at $C$ to open outward; and $B$ having its valve at $D$ to open inward.

Now suppose there be wo of those syringes placed side by side as at fig. 2, the tubes torether; thus, $A$ in the one syringe must be placesl by the side of $\mathrm{B}$ of the other, placing the tubes together, whose valves open contrary to each other.

In order to try the efficacy of this plan, have a comirion bladder, and into the neck of it pass either of two tubes which are connected, and let the piston handles be fastened together; then, as you raise and depress them, the bladder will expand and contract: you will perceive that by the upstroke of the pistons, the Vol. 59 . No.287. March 1822. 


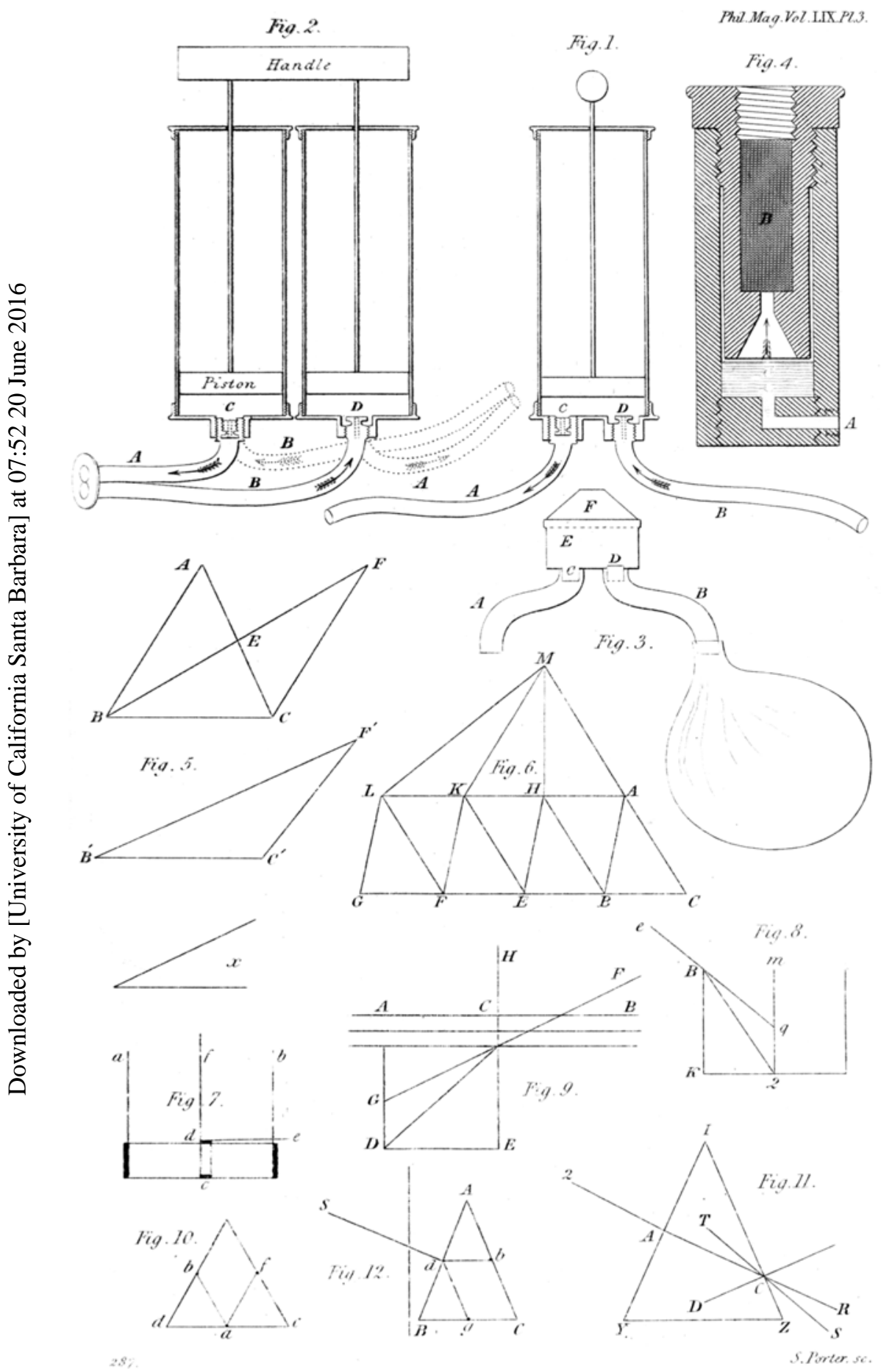


air passes from the atmosphere into the one syringe, whilst the air contained in the bladder is passing into the other syringe: now, as the pistons are depressed, the airs which the syringes contain are thus disposed of: that syringe which drew air from the atmosphere injects it in to the bladder, whilst the other syringe which drew air from the bladder, injects it into the atmosphere, and thus an artificial respiration is obtained, and a continual supply of fresh air nay be passed into the lungs; which might be either the conimon atmospheric air, oxygen, or any mixture, provided the proper tube be attached to the vessel which contains the gas.

The various uses to which these syringes are applicable I will not minutely detail, but only mention briefly a few. First, exhaustion by either syringe when separate. Second, condensation. Third, exhaustion and condensation at the same time. Fourth, when the syringes are combined as above described, a change of the atmosphere which occupies the vessel in that to which they are attached. Fifth, if the two syringes are put together, so that the $A$ tube of each syringe shall be inserted into separate vessels containing liquor or gases, whilst the other tubes B $B$ are inserted juto a third vessel, as the pistons are worked the liquor or gases will be drawn from the vessel containing the tubes $A A$, and be mixed in the vessel containing the tubes $B B$, which may be applied as a gas-blowpipe.

When the svringes are for the purpose of restoring suspended animation, it inight be well to inclose one of them with a case to contain hot water, similar to the description given by Mr. J. Murray; but I should also propose that the tubes $A$ and $B$, which are to be placed into the nouth, have valves in them; thus the tube $A$ might have a valve near $C$ to open into the atmosphere, which may be loaded or have a spring to prevent its opening when the lungs are not strained: but should a pressure be given which would be injurious to them, the valve would then open, and thus prevent it. 'The tube $B$, which also enters the mouth, may bave a valve near $\mathrm{D}$ to open inwardly, and be similarly loaded or rotained by a spring, to prevent the rarefaction within the lungs from being so complete as to endanger a rupture of any of the small vessels.

The same sort of valves may be applied to the breathing the nitrous oxide, so as to ensure its not passing to the lungs a second time, which I consider to be injurious to the individual performing the experiment.

Let $\mathrm{E}$ (fig. 3 ) represent the lower part of a syringe with its tubes either flexible or otherwise, and having valves as before described. Let $F$ be a mouth-piece. Suppose a bladder containing the gas be attached to the tube $\mathrm{B}$, and an individual in 
the act of irhaling the gas, it would pass from the bladder into his lungs, and when he exhaled, the breath would pass through the other tube that has the valve to open outward into the air.

Pratten's Row, Lawrence Hill, Bristol, I remain respectfully, \&c. Jan. 10, 1822.

John Moore, Jun.

XXXIX. Process for procuring pure Platinum, Palladium, Rhodizu, Iridium, and Osmium, from the Ores of Platinum. By M. Baruel, Chemical Operalor in the School of Medicine al Paris*.

1. $\mathbf{T}_{\text {wo sorts of platinum ore occur in commerce, one of which }}$ is white and brilliant, the otlier is blackish coloured. The latter contains much more iron $\uparrow$ than the preceding; both ores exist always in the form of small spangles, which vary in size ; platinum ore is one of the most compound known: besides the five metals abope noted, several others are found in it, especially two kinds of ferruginous sand, one of them attractible by the magnet, the other not, and which is a combination of the oxides of titanium and iron : there is, besides chromate of iron, some copper, particles of gold alloyed with silver, with copper, and mercury. It contains, moreover, some sulphuret of lead and copper. We may henee judge of the singular complexity of this mineral, and be ready to acknowledge that its exact analysis, in regard to the proportion of its constituents, is nearly impossible. In order to separate the platinum, palladium, rhodium, iridium, and osmium, from each other, and the rest of the bodies, the following method is the one which long experience has proved most successful.

2. The ore is triturated in a cast-iron mortar for a considerable time, during which a stream of water is constantly passed over it, to wash away the ferriferous sand, the titanite, and chromate of iron, reduced to an impalpable powder. When the ore is very brilliant, it is left to settle for an instant; the water is decanted off, and it is then exposed in a crucible to a red heat during a quarter of an hour. The whole mercury is thus volatilized, when we can readily distinguish the spangles of alloy of gold and copper by their colours.

3. The calcined ore being introduced is to a tubulated retort, we pour over it half its weight of nitro॰muriatic acid (aqua regia)

* From Mr. Brande's Journal of Science. This valuable memoir derives peculiar interest from the large importation of the aiove ore daily expected from Sopth America, in consequence of the negotiation between $\mathbf{M}$. Zea and some London merchants.

+ Rather, the fine black powder, or ore of iridium and osmium, noticcd in paragraph 3.-Tr. 